\title{
Continuidad y cambio en la organización de los espacios arquitectónicos de Huaca de la Luna y Plataforma A de Galindo, costa norte del Perú
}

Continuité et changement dans l'organization des espaces architecturaux de Huaca de la Luna et Plate-forme A de Galindo, côte nord du Pérou Continuity and change in the organization of the architectural spaces of Huaca de la Luna and Platform A of Galindo, northern coast of Peru

Jorge Gamboa Velásquez

\section{OpenEdition}

Journals

Edición electrónica

URL: http://journals.openedition.org/bifea/5409

DOI: $10.4000 /$ bifea.5409

ISSN: 2076-5827

Editor

Institut Français d'Études Andines

Edición impresa

Fecha de publicación: 1 agosto 2005

Paginación: 161-183

ISSN: 0303-7495

Referencia electrónica

Jorge Gamboa Velásquez, « Continuidad y cambio en la organización de los espacios arquitectónicos de Huaca de la Luna y Plataforma A de Galindo, costa norte del Perú », Bulletin de I'Institut français d'études andines [En línea], 34 (2) | 2005, Publicado el 08 agosto 2005, consultado el 01 diciembre 2020. URL : http://journals.openedition.org/bifea/5409; DOI : https://doi.org/10.4000/bifea.5409

\section{cc)}

Les contenus du Bulletin de l'Institut français d'études andines sont mis à disposition selon les termes de la licence Creative Commons Attribution - Pas d'Utilisation Commerciale - Pas de Modification 4.0 International. 


\title{
Continuidad y cambio en la organización de los espacios arquitectónicos de Huaca de la Luna y Plataforma A de Galindo, costa norte del Perú
}

\author{
Jorge Gamboa Velásquez*
}

\begin{abstract}
Resumen
La perspectiva tradicional sobre la serie de eventos que demarcaron el tránsito entre el período Intermedio Temprano y el Horizonte Medio en el valle de Moche, señalaba el rápido abandono de Huacas del Sol y la Luna para dar paso a un nuevo centro urbano en Galindo. Las evidencias acumuladas en los últimos años indican que la ocupación de Huacas del Sol y la Luna se prolongó temporalmente más de lo pensado, y que parte de la arquitectura pública de Galindo —el conjunto de Plataforma A - presentaría reminiscencias claras de la planificación de una plaza pública de Huaca de la Luna. El artículo busca exponer las similitudes y diferencias entre sectores de ambos edificios, en el marco de la probable coetaneidad entre estos dos vastos asentamientos urbanos prehispánicos en la costa norte del Perú.
\end{abstract}

Palabras clave - Huaca de la Luna, Galindo, Plaza 1, Plataforma A, arquitectura pública, revitalización, cronología absoluta, continuidad cultural

\section{Continuité et changement dans l'organization des espaces architecturaux de Huaca de la Luna et Plate-forme A de Galindo, côte nord du Pérou}

\section{Résumé}

La vision traditionnelle d'une série d'événements qui ont marqué la transition entre la Période Intermédiaire Ancienne et I'Horizon Moyen dans la vallée de Moche montrait l'abandon rapide du site de Huacas del Sol et de la Luna lié au développement du nouveau centre urbain de Galindo. Les indices archéologiques accumulés pendant la dernière décennie indiquent que l'occupation du site de Huacas del Sol et de la Luna s'est prolongée beaucoup plus longtemps que ce que l'on avait 
pensé à l'origine. De plus, une partie de l'architecture publique de Galindo, soit le complexe de la Plate-forme A, présente des ressemblances marquantes avec la planification architecturale d'une place publique adjacente à Huaca de la Luna. Cet article tente d'exposer les similitudes et les différences architecturales des deux édifices, dans le cadre d'une contemporanéité entre les deux vastes centres préhispaniques de la vallée de Moche, sur la côte nord du Pérou.

Mots clés - Huaca de la Luna, Galindo, place publique, plate-forme, architecture publique, réaménagement, chronologie absolue, continuité culturelle

\title{
Continuity and change in the organization of the architectural spaces of Huaca de la Luna and Platform A of Galindo, northern coast of Peru
}

\begin{abstract}
Traditional perspectives concerning the series of events marking the transition between the Early Intermediate Period and the Middle Horizon in the Moche Valley indicate a rapid abandonment of the Huacas del Sol y Luna site, related to the development of the new urban center of Galindo. Archaeological evidence gathered during the last decade indicates a much longer occupation of the Huacas del Sol y Luna site. Moreover, architectural compound of Platform A at Galindo is reminiscent of a public plaza adjacent to Huaca de la Luna. The article examines architectural similarities and differences between these monumental compounds, in the framework of the contemporaneity between the two pre-Hispanic urban centers of the North Coast of Peru.
\end{abstract}

Key words - Huaca de la Luna, Galindo, plaza, platform, public architecture, refit, absolute chronology, cultural continuity

La arquitectura prehispánica es sin duda una fuente invaluable de información para la reconstrucción de los procesos culturales y del contexto histórico de poblaciones pretéritas. En el caso particular de la arquitectura que ahora podemos denominar pública, también es posible lograr una aproximación a aspectos como la planificación y uso de espacios que fueron concebidos, erigidos, y empleados mediante esfuerzos corporativos. A lo largo de su funcionalidad, estos espacios arquitectónicos permitieron el desarrollo de la interacción social y el consiguiente establecimiento de las instituciones sociales, pero también pasaron a ser parte integral en la reproducción de esas instituciones (Moore, 1996: 3, 10, 219), y no únicamente la materialización de un epifenómeno cultural que implicaba la puesta en práctica de los proyectos arquitectónicos.

Trataremos sobre dos casos de arquitectura monumental de función pública en los sitios de Huacas de Moche y Galindo, ambos en el valle de Moche (fig. 1). Huaca de la Luna y Plataforma A presentan escenarios geográficos y condiciones de preservación ciertamente distintos, sin embargo el estudio de su arquitectura permite poner en práctica un análisis que busca contribuir al debate sobre la relación entre ambos asentamientos y sus residentes. La arquitectura en estos sitios se constituye en evidencia de procesos culturales que se reflejaron en diferentes grados y de distintas maneras en la construcción de estos espacios públicos. No podemos esperar que ellos por sí solos revelen la complejidad estructural y conductual de las poblaciones implicadas, pero creemos que brindan la oportunidad para examinar y correlacionar diversas clases de evidencia en el registro material de la sociedad Moche.

El complejo cultural Moche o Mochica es considerado una expresión sobresaliente de la consolidación de formas de organización sociopolítica compleja en la costa norte de Perú durante gran parte del Intermedio Temprano hasta inicios del Horizonte Medio (aprox. $100 \mathrm{~d}$. 


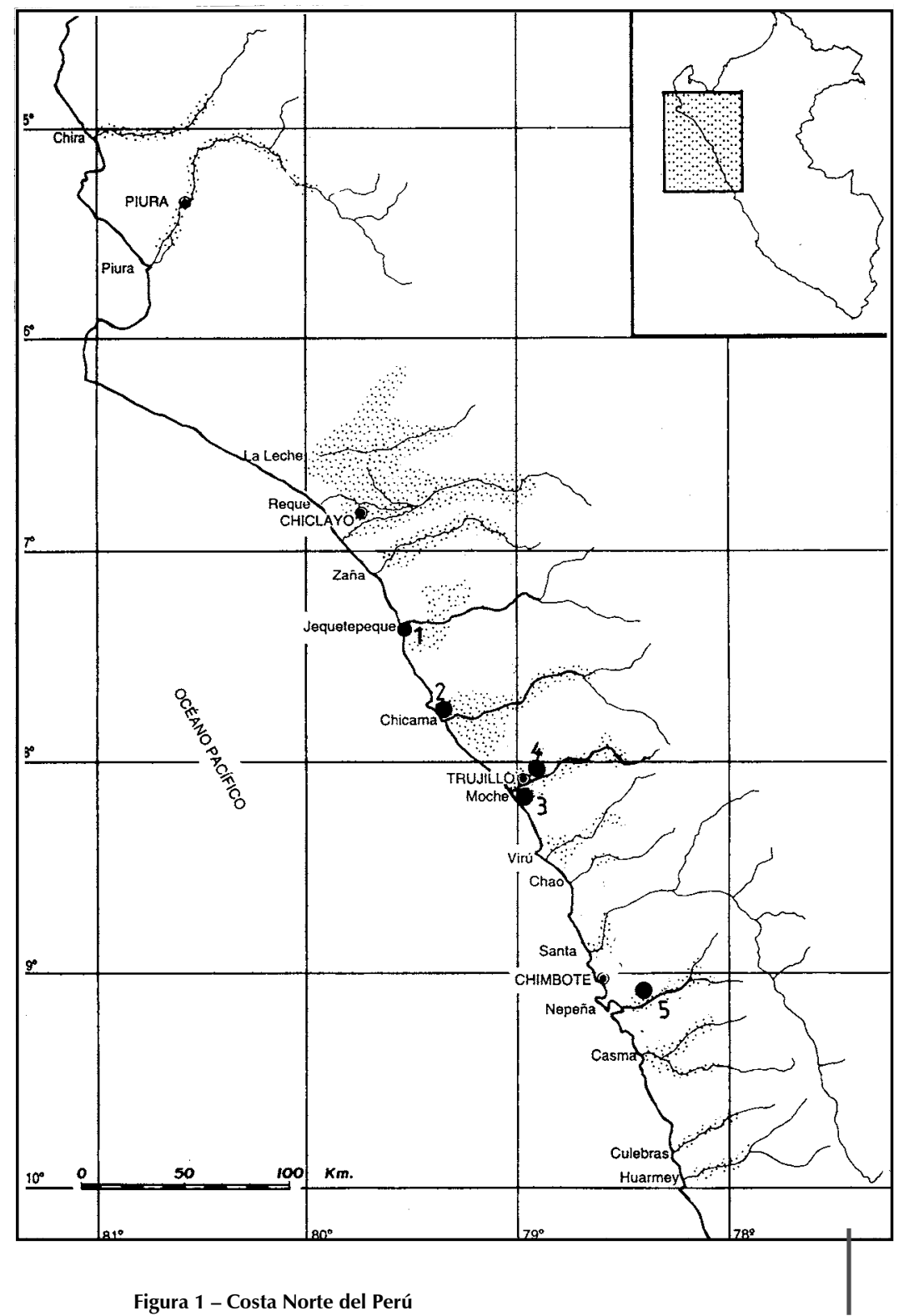

1. Dos Cabezas; 2. Cao Viejo; 3. Huacas de Moche; 4. Galindo; 5. Pañamarca

C.-750 d. C.) con un desarrollo de entidades, compartiendo prácticas ideológicas, religiosas y artísticas, pero que también pudieron competir por imponer ensayos de centralización política al nivel de valles y sectores específicos de la región.

El tema de la datación ciertamente aún incorpora una serie de problemas de correlación de fechas absolutas y secuencias estratigráficas o variantes estilísticas para el esclarecimiento de secuencias locales y regionales, y, a partir de ello, lograr interpretaciones procesuales e históricas. 
Desde los tiempos de Larco (1948) se ha avanzado en la comprensión de un desarrollo del universo cultural Moche más diversificado de lo supuesto en tiempo y espacio, con dos grandes áreas: Moche Norteño y Moche Sureño, separadas por el Desierto de Paiján, que evidencian complejos distintos de evolución estilística y política (Castillo \& Donnan, 1994).

La sección meridional Moche puede ser apreciada como un escenario cultural que experimentó un crecimiento notable del área de influencia Moche a partir de la Fase III, cuando ocurren evidencias de una intensa integración cultural y política entre los valles de Moche y Chicama y el área entre Virú y Huarmey, que sin embargo no excluía la existencia de variables al nivel del grado de incorporación al complejo cultural Moche. Así, mientras los valles al sur de la intercuenca Moche-Virú presentaban formas diversas de impacto de la presencia Moche y respuesta local durante las Fases III y IV, los valles de Moche y Chicama experimentaban durante más tiempo la transformación social Moche Sureño. Las Fases IV y V en esta parte de la costa norte han sido identificadas principalmente a partir de asambleas de artículos de élite, la organización de construcciones públicas, y el rango y densidad en la distribución regional de estos elementos. Mientras la Fase IV habría estado ligada a una consolidación de un orden Moche en la mayoría de estos valles con el sitio de Huacas del Sol y la Luna como sitio, desarrollando hegemonía sobre la sección meridional Moche (Chapdelaine, 2003; Moseley, 1992; Shimada, 1994a), la Fase $V$ pudo atestiguar la reducción del área sureña — debido al repliegue de la presencia Moche y la emergencia de entidades locales - y la consolidación del poder de una entidad en la sección alta del valle de Moche, portadora de un nuevo estilo; considerándose entre 600 y $700 \mathrm{~d}$. C. como el período de tránsito para la ocurrencia de estos cambios en el panorama regional.

La acumulación de nuevos datos ha conllevado a reevaluar algunas de las premisas sobre el desarrollo de la población Moche en cada una de estas fases y durante la transición entre ellas. Particularmente los temas del desarrollo del urbanismo, la formación del Estado y la dinámica de las idiosincrasias de grupos humanos dominantes o comunes, han sido examinados con el fin de lograr aproximaciones con fundamento empírico y epistemológico a la historia Moche. La investigación sobre la arquitectura Moche ha incluido tanto las construcciones domésticas y áreas de producción urbana (Bawden, 1982; Chapdelaine, 2001) como edificaciones de función religiosa o gubernamental (Uceda \& Tufinio, 2003; Bawden, 1982; Bourget 1998). Esto permitió reconocer los rasgos distintivos de cada modalidad de espacio cultural, y lleva a considerar una serie de aspectos teóricos necesarios para el análisis de los edificios dotados de áreas de factible carácter público.

\section{ARQUITECTURA PÚBLICA, IDEOLOGÍA Y MEMORIA}

La arquitectura conceptualizada como pública, alcanza a incorporar una multiplicidad de formas de espacio. Como arquitectura pública es posible denominar en un sentido amplio una serie de edificios y áreas arquitectónicas que colectivamente eran escenario de interacciones sociales que por sus características organizativas (número de participantes, diversidad de niveles en la percepción de discursos o grado de repercusión social de las actividades) sobrepasaban el ámbito de aquellas desarrolladas en la residencia doméstica. Es crucial reconocer que la denominación pública debe ser entendida a través de dos niveles de definición conceptual: a) esta arquitectura podía reflejar la participación conjunta de grupos humanos diferenciados en posición socioeconómica, conducta e intereses; y b) esos mismos espacios incorporaban diversos niveles de accesibilidad al público de las actividades allí desarrolladas y por ende, de su significado y simbolismo.

Una característica principal de las edificaciones públicas es su construcción mediante esfuerzos corporativos, que involucraban la participación de grupos masivos de trabajadores, especialistas en tecnología y líderes sociales. Esta multiplicidad en la identidad de los constructores ciertamente no es isomorfa con la de los posteriores usuarios, pudiendo ocurrir una asimetría social inherente a la función de los espacios, aún aquellos más adecuados para la puesta en práctica de discursos ideológicos masivos.

La perspectiva usual sobre el rol de la arquitectura pública es su identificación como el vestigio material de formas de comunicación a través de las cuales grupos de élite y el resto de las poblaciones elaboraban y evaluaban formas de interacción social e identidades (Bawden, 
2001: 285; Uceda \& Canziani, 1998). Asentamientos dotados de grandes obras arquitectónicas también pueden ser identificados como centros de actividad de jerarcas que exponían parte de su capacidad en manejo de recursos y liderazgo social en la construcción de espacios monumentales que demarcaban el paisaje natural o urbanístico (Demarais et al., 1996).

La arquitectura ceremonial es una categoría de arquitectura pública concebida para reflejar simbolismos y preceptos ideológicos sacros que alcanzan un grado de consenso social, pero que suelen aparecer localizados en personajes prominentes: oficiantes de culto, funcionarios administrativos $\mathrm{o}$, como es posible en el caso Moche, jerarcas desarrollando ambas funciones (Moseley, 1992; Chapdelaine, 2001: 80-83; Topic, 1982). Esta arquitectura podía adquirir volúmenes realmente masivos, pero creemos que la variabilidad en tamaño o elaboración debe ser considerada conjuntamente a los grados de accesibilidad para evaluar el rol de estos espacios en el ejercicio de la autoridad.

La presencia en algunos asentamientos principales Moche de grandes plazas amuralladas apunta hacia formas de comunicación que incorporaban estrategias de inclusión de grupos humanos masivos en la observación de actos ceremoniales públicos y la parafernalia asociada, asimismo podría indicar un énfasis en mantener espacios que contribuían al reconocimiento de pertenencia a una identidad colectiva, por medio de organizaciones corporativas, relaciones de parentesco o comunión religiosa. Este tipo de lazos sociales era maximizado durante períodos de amenaza externa (Bawden, 2001: 286), pero creemos que también acentuaban su efectividad bajo un régimen funcional en principio preestablecido de concentración masiva de público en áreas sacralizadas. Podemos asumir que la agenda del funcionamiento de estos edificios era básicamente la difusión de preceptos de la ideología dominante promotora de la cohesión, pero que también permitía distintos niveles de experiencia sobre liturgias, iconos y performances públicas por parte de los diversos componentes socioeconómicos de la población.

Los estudios sobre ideología y prácticas de gobierno Moche han contribuido a examinar símbolos y actividades identificadas como peculiares al desarrollo de las instituciones estatales y la diferenciación social (Uceda, 2001; Campana \& Morales, 1997; Bawden, 1994; 2001; Shimada, 1994a). A ello se ha sumado el interés más reciente en los procesos de integración urbe-ruralidad y en la identidad comunitaria frente a aquella promovida por organizaciones centralizadoras y que ensayan dominio (Bawden, 2001; Dillehay, 2001). Creemos que esto promoverá el desarrollo de perspectivas holísticas sobre el funcionamiento y la repercusión social de la arquitectura ceremonial y pública donde ocurría la interacción entre distintos niveles socioeconómicos, y que puede ser vital para la identificación y evaluación de instituciones políticas auspiciadoras de centralización administrativa y continuidad en el gobierno. La viabilidad de un orden gobernante puede estar condicionada por su identificación con dogmas reconocidos y sancionados por diversos componentes socioeconómicos de una población (Bawden, 2001: 293), y ello podía implicar la creación de áreas adecuadas para lograr la concentración de grandes grupos humanos.

Pero las algunas plazas amuralladas Moche no habrían sido espacios que expresaran relaciones heterárquicas. Sus extensas áreas llanas contrastaban con áreas adjuntas estrictamente cerradas, capaces de brindar privacidad para relaciones altamente jerarquizadas y menos públicas. En estas plazas podía ocurrir una complementariedad entre áreas realmente públicas, donde el público se agrupaba e interactuaba con jerarcas u oficiantes religiosos, y sectores destinados al encuentro entre representantes de estos grupos.

La evidencia iconográfica indica que la manipulación de símbolos e imágenes de divinidades del estilo Cupisnique (aprox. 1500-400 a. C.) por los Moche pudo constituirse en una forma de proclamación de lazos de continuidad ideológica y artística con manifestaciones regionales del Horizonte Temprano (Campana \& Morales, 1997). Esto podría ser apreciado como un arcaísmo, pero su recurrencia parece expresar una continuidad en la imaginería y simbolismo entre ambos períodos (Cordy-Collins, 1992). La recuperación de representaciones pretéritas de poder en la producción iconográfica y artística es un aspecto relevante a la evolución de las tradiciones de la arquitectura ceremonial. En el caso Moche es factible que parte del poder de algunos oficiantes del culto y líderes religiosos radicara en la proclamación de lazos de continuidad ideológica con centros locales o regionales más tempranos, obviamente en la perspectiva propia de los jerarcas 
que al seleccionar antiguos diseños posiblemente recreaban su carga simbólica. En Huaca de la Luna esta práctica se habría caracterizado por la reproducción del poder sacerdotal y del culto a deidades ancestrales de las montañas a través de eventos cíclicos de reafirmación de posiciones jerárquicas mediante el enterramiento de oficiantes y de la propia arquitectura, con sucesivas reediciones a mayor escala del espacio público y sacralizado (Uceda, 2001; Makowski, 2003).

\section{LA TRANSICIÓN MOCHE IV-V: MODELOS TEÓRICOS Y EVIDENCIA ARQUEOLÓGICA}

El tema de las modificaciones culturales durante las fases finales de la sociedad Moche ha sido un importante punto de interés en la arqueología andina, habiéndose presentado varios modelos teóricos que intentan aproximarse al proceso que originó la desarticulación final de los moche como la tradición dominante en la costa norte. Estos modelos enfatizaron diversos aspectos del cambio cultural a partir de la noción de reorganización al interior de los grupos Moche $\mathrm{V}$ o Tardío como respuesta a factores sociales y naturales de profunda repercusión ocurridos al final de la Fase Moche IV. Dos tendencias prevalecieron en estas propuestas: la primera veía al fenómeno cultural Wari como el mayor elemento dinámico en este proceso, la segunda tendencia, en cambio, propulsó la investigación de la estructura sociopolítica Moche como medio para explicarlo (Bawden, 1994; 1996).

Quienes incidieron en la influencia de Wari sobre Moche incluyeron entre los fundamentos de su propuesta la aparición sobre la costa norte de elementos estilísticos de la sierra y costa centrales (Menzel, 1964; Donnan, 1968) y la aparente inserción de modelos arquitectónicos del supuesto origen en tradiciones urbanas serranas (Schaedel, 1951). Una supuesta influencia Wari sobre el territorio Moche como explicación para los cambios perceptibles en el registro material de la transición Moche IV-V se ha reevaluado en los últimos años, y en la actualidad se reconoce la existencia de contactos localizados entre ambas sociedades a través del intercambio de bienes elaborados y símbolismos iconográficos (Castillo, 2001), pero también que no es perceptible una repercusión mayor de Wari en la organización sociopolítica Moche.

La posición alternativa ha dado prioridad al estudio de los sitios vigentes durante la Fase V, como Pampa Grande (Haas, 1985; Shimada, 1994b), Galindo (Bawden, 1977; 1982; 2001) y San José de Moro (Castillo, 2001), contribuyendo a determinar cómo los mecanismos de reacción de los componentes estructurales de la sociedad Moche a estímulos internos y externos permiten explicar el carácter innovador de la Fase Moche V, la cual aparece demarcada tanto por rasgos estilísticos en la producción artesanal como por cambios en las estructuras políticas e ideológicas de la población norcosteña. Esto habría incluido desde 600 d. C. la reducción del área Moche, el cese en la vigencia de antiguos sitios principales y la aparición de nuevos asentamientos afiliados a nuevas tradiciones artísticas corporativas.

Los trabajos en Galindo contribuyeron en gran medida a establecer un enfoque analítico centrado en el examen exhaustivo de los datos arqueológicos, así como en elaborar una aproximación histórica que recalcó la diversidad en el tiempo y espacio como axioma para esclarecer el proceso de esta civilización andina (Bawden, 1994; 1996). La estructura ideológica de Galindo fue definida por la presión conjunta de otras entidades y de factores internos de estrés social (Bawden, 1983: 230-231; 1994: 405), originando que su arquitectura reflejara la estricta separación de componentes socioeconómicos del asentamiento y una dicotomía entre edificios seculares y centros de actividad religiosa. Estos últimos por su ubicación en la periferia del sitio y sus dimensiones menores a aquellos anteriores a la Fase $V$ fueron identificados como expresiones de una autoridad religiosa disminuida por una competitiva clase secularizada y desligada de preceptos ideológicos tradicionales.

Faltaba aún documentar mayores características de la arquitectura monumental previa a la Fase V. Hasta 1990 se conocían algunas características de la organización del trabajo en la arquitectura corporativa (Hastings \& Moseley, 1975), la distribución regional y rasgos generales del diseño de sitios monumentales (Reindel, 1993), y la decoración mural en varias construcciones 
ceremoniales (Mackey \& Hastings, 1982). Los proyectos a largo plazo develaron en mayor grado las características formales, tecnológicas y funcionales de la arquitectura Moche en Huaca de la Luna (Uceda \& Tufinio, 2003), Huaca Cao Viejo (Franco et al., 2003) o Sipán (Alva \& Donan, 1993). Las excavaciones en los dos primeros sitios han definido su naturaleza como centros ceremoniales y lugares de culto, y han documentado evidencias iconográficas y contextuales del desarrollo y significado de ritos sacrificiales y funerarios de la religión Moche, pero no han aportado vestigios contundentes del uso de estas construcciones monumentales como espacios residenciales a tiempo completo para miembros seculares o no seculares de la élite Moche. La función parcial de Plataforma I y plazas asociadas en Huaca de la Luna como viviendas sacerdotales no es improbable, pero ello debió suceder en condiciones distintas a las de residencias de élite como aquellas presentes al oeste de Huaca de la Luna (Chapdelaine, 2001), incluyendo este carácter la ausencia en el templo de implementos y áreas para la preparación de alimentos, y sectores para el almacenamiento de productos y la acumulación estacionaria de desechos.

Por otro lado algunos centros ceremoniales Moche experimentaron la acción de eventos pluviales que afectaron su arquitectura monumental (Uceda \& Canziani, 1993; Shimada, 1994a). Pero estos fenómenos pluviales no explican el abandono final de los edificios, que pudo suceder en función a coyunturas y procedimientos particulares. En Cao Viejo, el registro indica el desmantelamiento parcial de estructuras de adobe tras un fenómeno pluvial (Franco et al., 1994), mientras que en Huaca de la Luna el cese de funcionamiento del complejo habría implicado el sellamiento por los moche del ingreso a la plaza principal (Aguilar et al., 1999: 152; Uceda \& Tufinio, 2003: 186, 215).

La correlación de estos datos conduce a comprender que el surgimiento y abandono de asentamientos principales puede ser entendido como un complejo proceso de movimiento de algunos linajes de élite y grupos de residentes en asentamientos urbanos y ceremoniales o de centros menores en el hinterland, paralelamente al decaimiento en la viabilidad de sitios antiguos para seguir manteniéndose como centros de actividad política e ideológica, posiblemente en un contexto regional donde los cambios en normas culturales y organización jerárquica no ocurrían sincrónicamente y de manera uniforme.

\section{HUACA DE LA LUNA Y PLATAFORMA A DE GALINDO: ARQUITECTURA E INVESTIGACIONES ARQUEOLÓGICAS}

El conjunto de Huaca de la Luna se encuentra en la falda occidental del Cerro Blanco, cerca al extremo oriental del asentamiento de Huacas de Moche, en el valle bajo de Moche (fig. 2). Cubriendo un área de 290 m por 180 m (Uceda, 2001), su principal componente era la Plataforma I, que adquiría el carácter de un monumental eje para una serie de plazas cercadas y edificios masivos, incluyendo las Plataformas II y III al este y la Plataforma Uhle al oeste. El axis de la plataforma y plaza principales es de N $22^{\circ}$ E. Hacia fines del siglo VI d. C. la Plataforma I alcanzó a medir $90 \mathrm{~m}$ por lado, elevándose $30 \mathrm{~m}$ sobre la planicie ocupada por residencias al oeste. El frente principal al norte era precedido por la Plaza 1, de $175 \mathrm{~m}$ por $80 \mathrm{~m}$. El frontis de la plataforma presentaba un enorme conjunto de frisos y murales policromos dispuestos sobre sus terrazas, ocurriendo una rampa de acceso a la cima dispuesta transversalmente al frontis en su esquina nororiental. La cima de la plataforma estaba dividida entre los niveles alto y bajo, presentando ambos una serie de patios y recintos. El Nivel Alto contenía un altar aterrazado y un patio con galerías visibles desde la Plaza 1 (Uceda \& Tufinio, 2003).

Los fechados para Plataforma I datan la construcción del último edificio (Edificio A) hacia la mitad del siglo VI d. C. Uno de los fechados va de 419 a 610 d. C. (Uceda \& Canziani, 1998: 181), otros fechados sitúan al Edificio A entre la parte temprana y mediados del siglo VII d. C. (Chapdelaine, 2002: 78-79).

A diferencia de la Plataforma I, saqueada durante siglos y que, por lo tanto, no conserva gran parte de su último momento arquitectónico, la Plaza 1 ha preservado en mayor grado sus últimos componentes estructurales. Su planta no es estrictamente rectangular (el lado norte presenta cuatro 


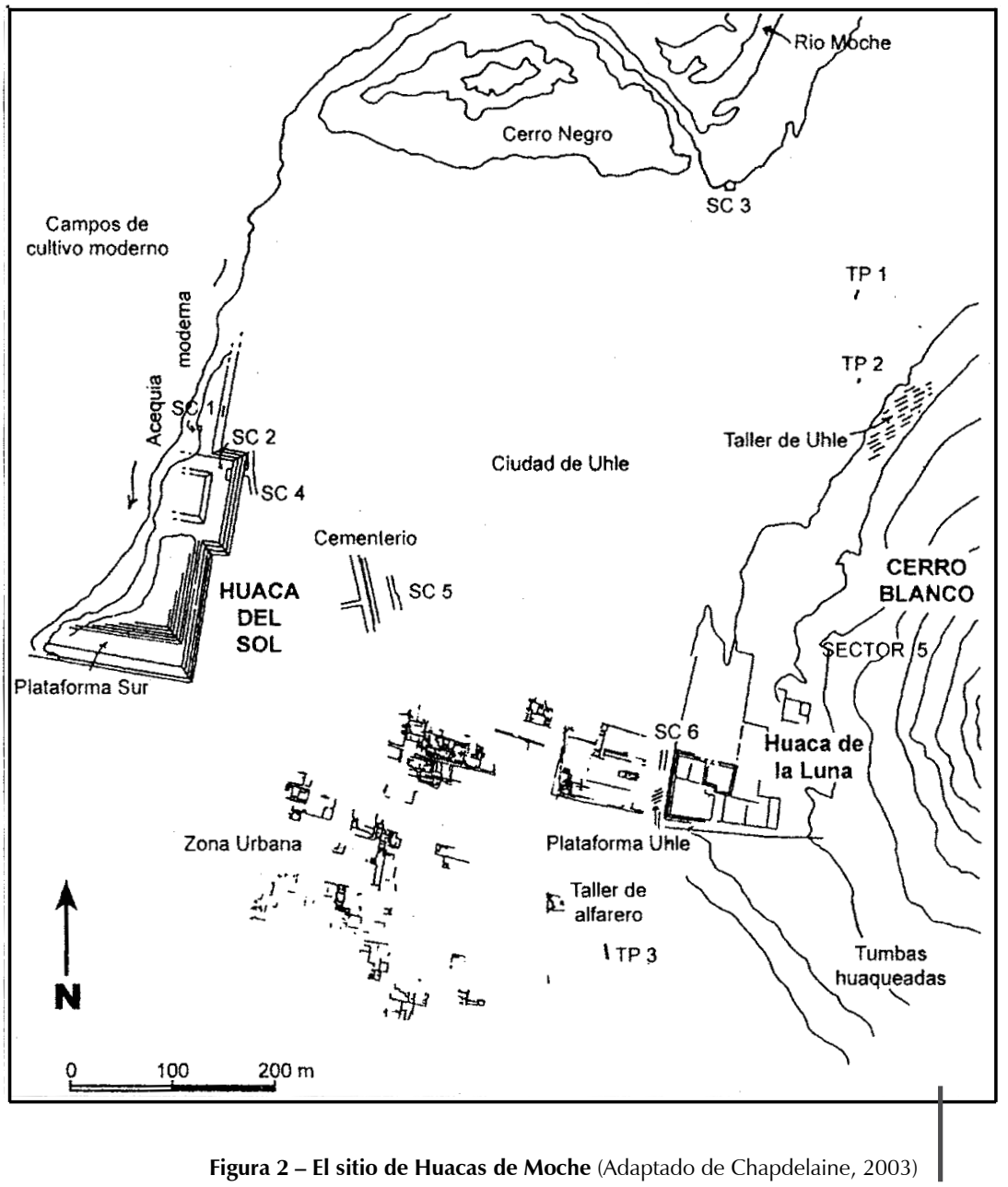

esquinas) y lo que denominaremos el sector este muestra menor longitud aunque es el más complejo arquitectónicamente. El sector oeste se presenta como un área mayormente llana que culmina al norte en el acceso a la plaza, conformado por un vano de 1,90 $\mathrm{m}$ de ancho, un corredor de $30 \mathrm{~m}$ de longitud, y un vano interior más estrecho y de umbral elevado. Al oeste del segundo vano se hallaba un recinto de $7 \mathrm{~m}$ por lado, conteniendo un estrecho corredor lateral interno y banquetas.

Los muros norte y oeste de Plaza 1 estaban reforzados por adosamientos de sección triangular y largas rampas decoradas con relieves. El sector oriental de la plaza presentaba dos terrazas superpuestas, de $3,5 \mathrm{~m}$ y $2 \mathrm{~m}$ de altura respectivamente. La primera muestra una planta compleja, siendo casi cuadrangular al norte y estrechándose al sur. La segunda terraza sostenía al Recinto 2 ( $13 \mathrm{~m}$ por $9 \mathrm{~m}$ ) y un pequeño tercer aterrazamiento. El recinto contenía un pequeño acceso indirecto y un patio con banqueta de rampa central, presentando murales geométricos y relieves de personajes humanos asidos de las manos en sus paramentos externos norte y sur respectivamente (Armas et al., 2003). La segunda terraza oriental permitía el acceso hacia la Plaza $2 \mathrm{~A}$ a través de una rampa empotrada y una monumental rampa adosada, ambas carentes de decoración mural. Las excavaciones en curso en el frontis norte de la Plataforma I también han develado la existencia de un recinto en la esquina sureste de la plaza. 
Las Plazas 2A, 2B, 3A, 3B y 3C decrecen dimensionalmente de norte a sur. Las dos primeras han producido evidencias de consumo ritual de coca y prácticas funerarias de élite (Uceda \& Tufinio, 2003: 188). Anteriormente al momento final de construcción y uso de Plataforma I algunos de estos espacios fueron escenario de sacrificios humanos (Bourget, 1998), tanto en un espacio abierto como en áreas conteniendo recintos y pequeños altares. Posteriormente, al menos la Plaza 3C fue sellada con arena y cubierta por un edificio de adobes, severamente afectado por actividades de huaqueros.

La Plataforma III y la probable plaza existente al oeste son los edificios ubicados a mayor altura del conjunto. A diferencia de otras construcciones próximas, la Plataforma III muestra un alto porcentaje de adobes con marcas incisas (Uceda \& Tufinio, 2003: 215), de modo similar a la última fase constructiva de Huaca del Sol. La Plataforma III estuvo decorada con pinturas murales policromas, incluyendo el célebre panel de la «rebelión de los artefactos».

La Plataforma Uhle, al oeste de la Plataforma I, consiste en una estructura masiva precedida por una plaza amurallada. Este sector ha reportado enterramientos de la élite Moche (Chauchat, 2000), y presenta áreas con relieves policromos y altares (Pimentel \& Alvarez, 2000). Al sur de esta plataforma se encuentran construcciones que a su carácter residencial habrían sumado funciones litúrgicas evidenciadas por la documentación de cráneos humanos modificados y depositados en hornacinas (Tello, 1998).

En Galindo (7 km tierra adentro del sitio Moche) el conjunto de la Plataforma A se ubica en el extremo este del asentamiento, sobre una llanura pedregosa cortada por cauces aluviales (fig. 3). El conjunto cercado presentaba una planta casi rectangular, de $264 \mathrm{~m}$ por $130 \mathrm{~m}$ (Conrad, 1974; Bawden, 1977) con un eje orientado a $\mathrm{N} 65^{\circ} \mathrm{E}$. El área cercada estaba dividida en una gran plaza al norte, la Plataforma A (50 m por lado y $13 \mathrm{~m}$ de altura) y plazas secundarias al suroeste y este. La plaza principal medía $180 \mathrm{~m}$ por 84 m, caracterizándose por una corta proyección de su esquina noreste. Nunca llegó a su cubierta por depósitos eólicos como en Huaca de la Luna, y el área central muestra un pequeño espacio rectangular hundido, similar a grandes rasgos de recintos documentados en la plaza de Cao Viejo (Franco et al., 1994). Los muros perimetrales al noroeste y noreste muestran una elevada banqueta adosada, y fueron decorados con pinturas policromas (Conrad, 1974). El muro noreste contenía dos vanos de acceso asociados a espacios internos semihundidos.

El lado oriental de la plaza estaba ocupado por estructuras masivas superpuestas, articuladas por rampas y corredores. La primera terraza presentaba una planta en $L$ invertida, mientras que la segunda de planta rectangular sostenía una pequeña estructura escalonada con dos niveles. El extremo sur del sector se unía a una esquina del edificio platafórmico, el cual presentaba en su cima una estructura de planta cuadrangular, afectada ahora por un forado de huaqueros. Sobre la cima también se aprecian muros de adobe y una pequeña estructura cercana al punto de unión con las terrazas orientales de la plaza.

La plaza suroeste, a la que se accede por una rampa lateral de la Plataforma A, presentaba bases de recintos de piedra en su sección norte y culminaba en un desnivel que permitía el paso a la plaza este, también presentando bases de estructuras menores de piedra. El muro perimetral noroeste de la plaza principal se prolongaba hacia la base de Cerro Galindo, restringiendo el paso hacia el conjunto desde el centro del asentamiento.

El inventario de materiales hallados sobre la Plataforma A incluyó restos humanos provenientes de enterramientos saqueados, cerámica fina y doméstica, restos vegetales, considerándose que evidenciaban el uso del conjunto como área residencial y funeraria para jerarcas de Galindo (Conrad, 1974: 232-233). El registro de entierros de jerarcas en edificios platafórmicos (Alva \& Donnan, 1993; Uceda \& Tufinio, 2003: 218-220; Franco et al., 2003: 163-165; Donnan, 2003) ha permitido reconocer una antigüedad mayor en la tradición de enterramientos de los miembros principales de la sociedad Moche al interior de estas construcciones, asociadas a grandes plazas frontales en los casos de Huaca de La Luna, El Brujo y Dos Cabezas. 


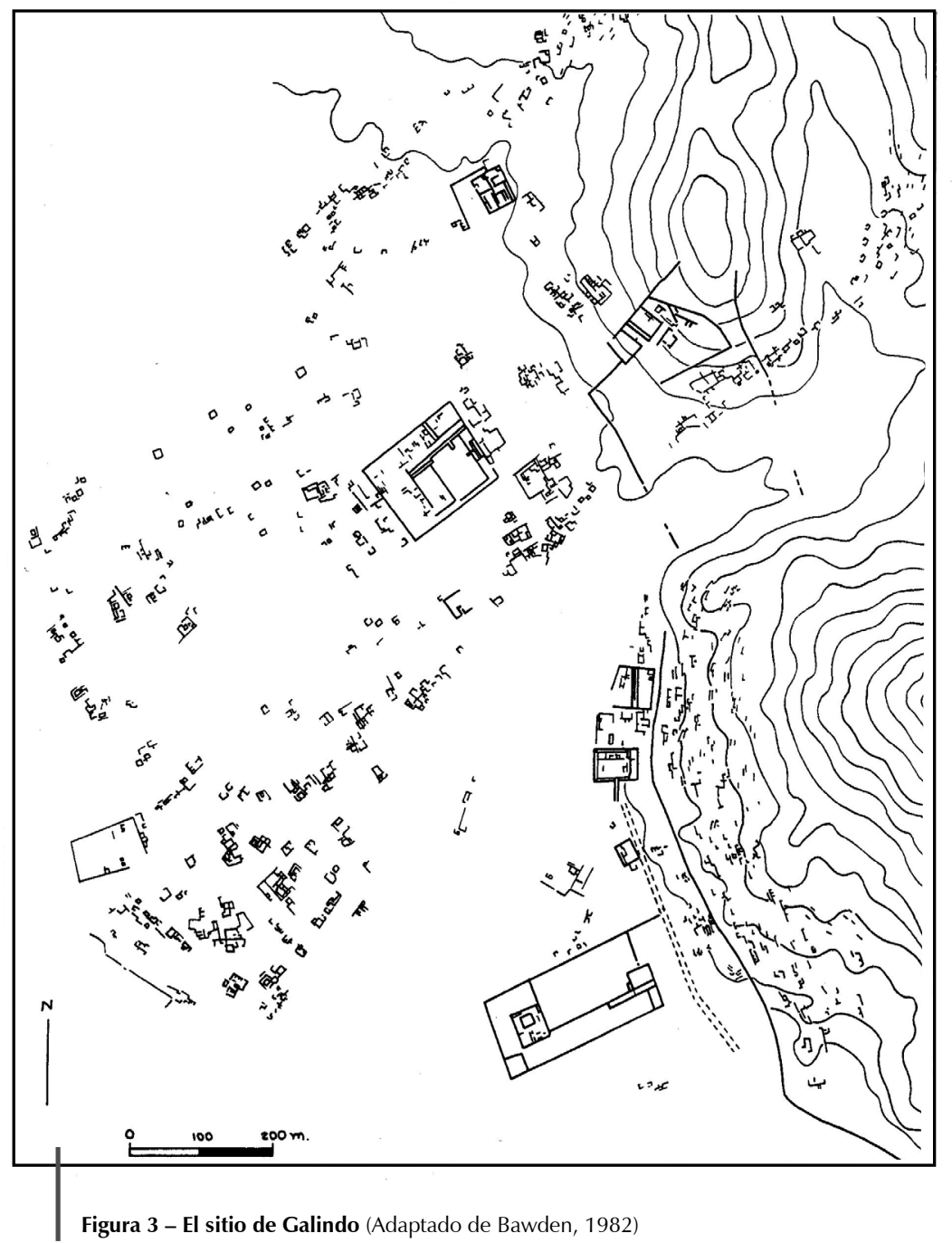

\section{HUACA DE LA LUNA Y PLATAFORMA A: UN CORRELATO ARQUITECTÓNICO}

La primera ocasión para revisar en perspectiva comparativa y diacrónica la organización arquitectónica de estos edificios ocurrió en 1999, cuando se excavó en la Plaza 1, con la supervisión de la Escuela de Arqueología de la Universidad Nacional de Trujillo y el Proyecto Huaca de la Luna dirigido por el Dr. Santiago Uceda y el Lic. Ricardo Morales (Aguilar et al., 1999). La comparación entre Huaca de la Luna —incluyendo ahora la Plaza 1-y el conjunto de la Plataforma A de Galindo (figs. 4 y 5) reveló notables similitudes y diferencias en la arquitectura de ambas construcciones, aspecto que fue presentado en el informe de las excavaciones (Aguilar et al., 1999: 138-140). 
Las similitudes en ubicación, diseño y articulación de elementos arquitectónicos entre estos conjuntos son:

a) Amplias plazas cercadas por muros monumentales que anteceden a los edificios platafórmicos, presentando ejes mayores orientados a puntos en el cuadrante noreste, asociadas en sus lados meridionales a la base de las plataformas y presentando un vano de acceso en sus extremos septentrionales, los cuales presentan prolongaciones parciales del área cercada.

b) Presencia de terrazas orientales, las primeras de planta en $\mathrm{L}$ invertida con una sección norte cuadrangular. En la Plaza 1, esta sección de la primera terraza mide 35,50 m por 20 m, y en la plaza de la Plataforma A, $40 \mathrm{~m}$ por $25 \mathrm{~m}$. En cada caso, el lado sur de estas terrazas (paralelo y confrontado al frontis de las plataformas) presentaban rampas adosadas que las articulaban con el piso de las plazas.

c) El lado oeste en cada primera terraza oriental estaba delimitado en la cima por un ancho amurallamiento.

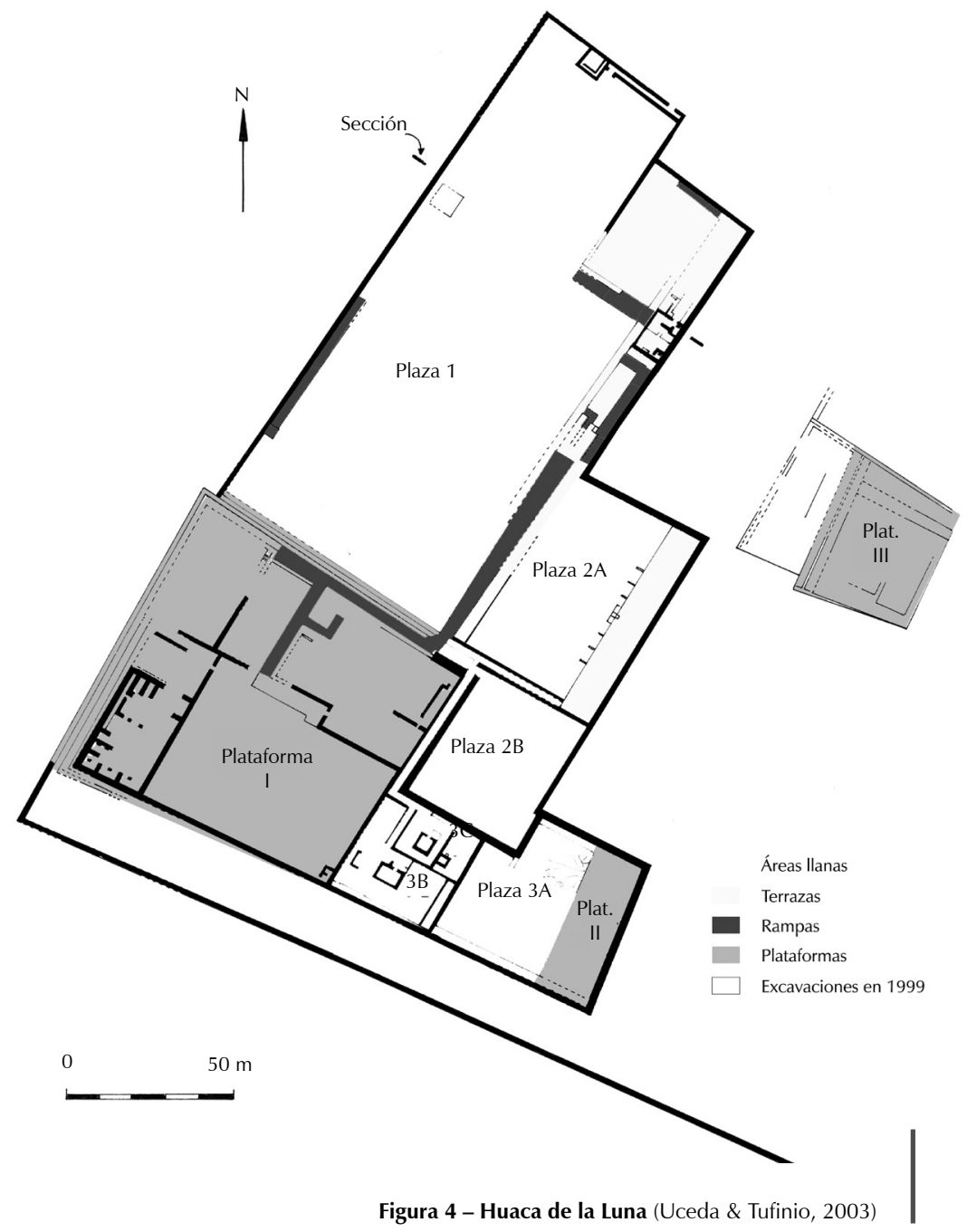




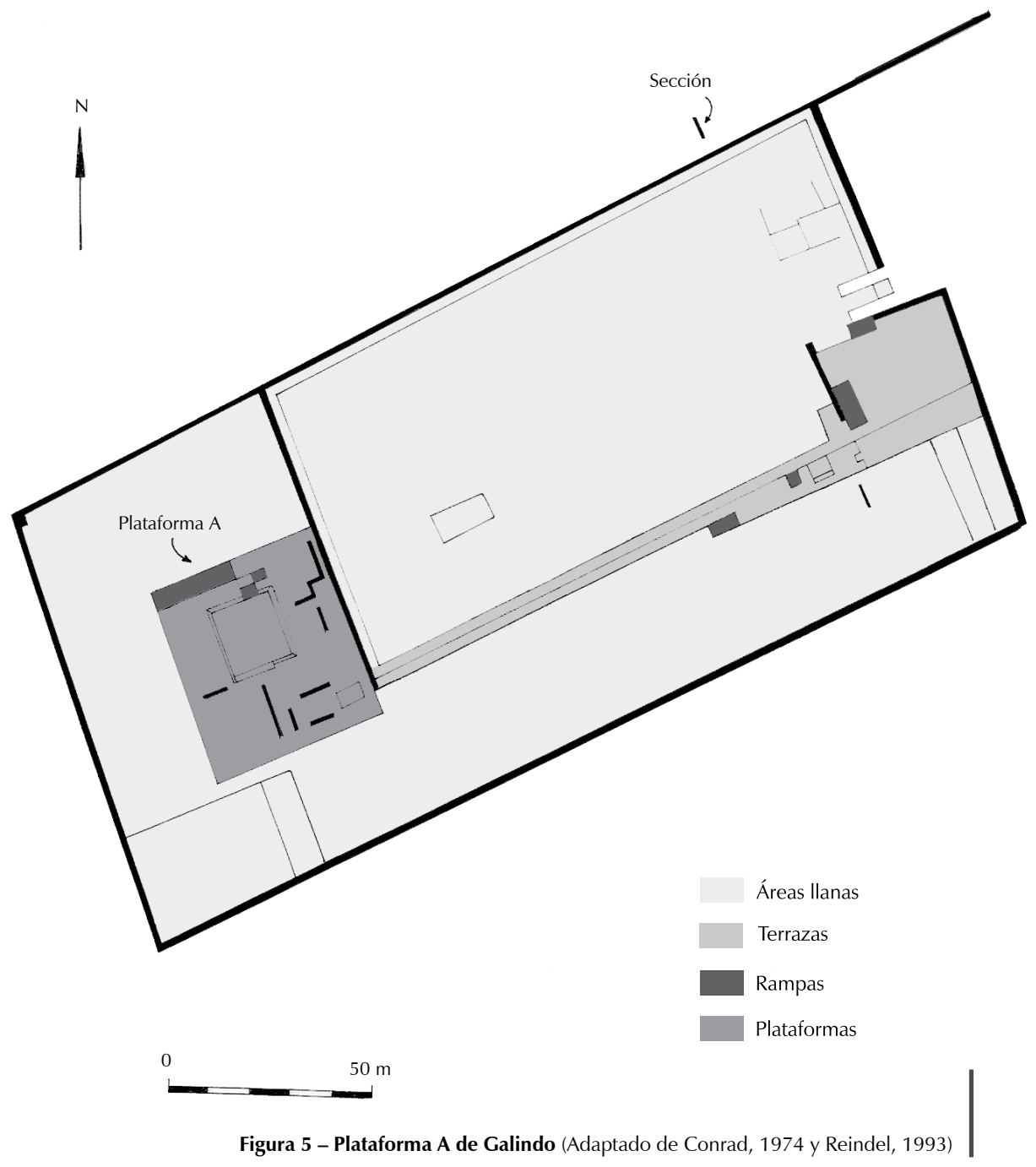

d) El lado sur de los sectores orientales en cada plaza presentaba la prolongación más estrecha de la primera terraza, a la cual se superponían un segundo aterrazamiento de planta rectangular y estructuras menores.

e) La articulación entre ambos niveles aterrazados era lograda mediante rampas empotradas (que corrían al interior de seccionamientos estrechos del aterrazamiento) ubicadas en puntos similares.

La presencia de recintos adosados al lado interno del muro septentrional en proximidad a los accesos a las plazas principales es difícil de evaluar como un rasgo común, considerando la probable cronología posterior al uso del conjunto de la Plataforma A para aquellos presentes en su plaza frontal (Conrad, 1974: 229-230). El acceso a la cima de las plataformas podría evidenciar otra afinidad, la Plataforma I muestra una rampa adosada a la esquina noreste coincidiendo con el extremo sur del sector oriental de la Plaza 1, en la Plataforma A de Galindo podría ocurrir una configuración similar, pues un probable punto de acceso a la cima del edificio platafórmico se encuentra en su esquina este, exactamente sobre la sección final de las terrazas laterales. 
Ahora citemos las diferencias arquitectónicas. La más notable es el reducido tamaño de la Plataforma A en comparación a la Plataforma I de Huaca de la Luna durante su última edificación. Asimismo, los muros perimetrales del conjunto de la Plataforma A crearon una vasta cercadura rectangular, lo cual no sucedió en Huaca de la Luna, donde se configura una planta con múltiples esquinas y que asemeja la forma de un escalón. Una tercera diferencia notable es el diseño del ingreso a las plazas mayores, que en la Plaza 1 adopta la forma de un largo corredor que finalizaba en un umbral elevado, en cambio en Plataforma A el ingreso era dual y conducía directamente a áreas articuladas al nivel de la plaza mediante rampas de escasa pendiente.

De lo expuesto es posible recalcar dos aspectos. Primero, las similitudes entre los edificios en cuestión se concentrarían en las plazas de mayor amplitud, especialmente en uno de sus espacios laterales (fig. 6). En segundo término, las diferencias en el planeamiento arquitectónico estaban presentes en la magnitud y diseño de las áreas cercadas de menor tamaño y plataformas.

Las similitudes arquitectónicas entre la Plataforma A y Huaca de la Luna no ocurren si comparamos la Plataforma A con otras edificaciones que combinaron áreas cercadas con plataformas. Dos Cabezas, Huancaco o Pañamarca por ejemplo son edificios públicos compuestos por plataformas y plazas, pero no parecen referentes directos para la arquitectura de la Plataforma A de Galindo ${ }^{1}$. Cao Viejo merece atención puesto que el sector sur de su plaza frontal ha evidenciado ser formalmente similar a la Plaza 1. En Cao Viejo el frontis norte de la plataforma, el acceso a la cima y la organización de los ambientes sobre ella son semejantes pero no idénticos a Huaca de la Luna (Franco et al., 2003), pero podemos señalar que la correlación de fechas radiocarbónicas y la proximidad geográfica entre el sitio Moche y Galindo hace más factible la correlación entre estos sitios, manteniendo a Cao Viejo como un referente válido de ambos en el valle de Chicama.

\title{
5. EL ASPECTO FUNCIONAL DE LAS PLAZAS CEREMONIALES
}

La recurrencia de elementos arquitectónicos entre las plazas frontales de Plataforma I de Huaca de la Luna y Plataforma A puede significar una planificación semejante en el ordenamiento físico del espacio sacro, pero no necesariamente una dinámica funcional similar. Sin embargo, la correlación formal podría indicar que el tránsito en las plazas se rigió parcialmente a un modelo común, particularmente en cada sector oriental, donde rampas, corredores y terrazas configuraron los senderos a seguir por oficiantes y concurrentes a las ceremonias.

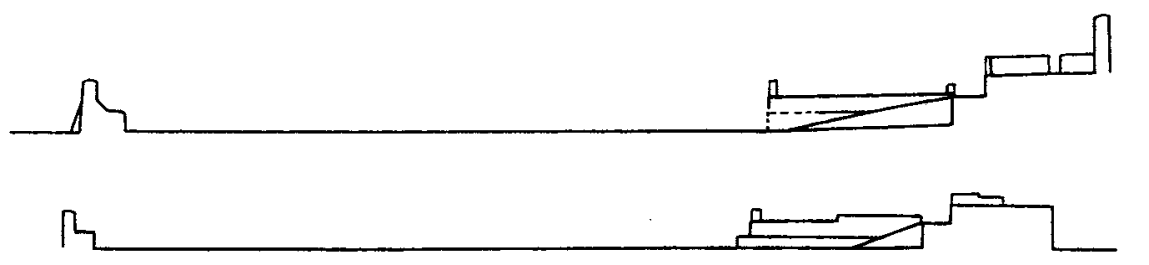

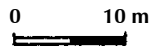 \\ Figura 6 - Secciones comparativas Este-Oeste de Huaca de la Luna y Plataforma A
}

1 La plaza de Dos Cabezas (Donnan, 2003) no comparte el diseño de la Plataforma A o Huaca de la Luna, al extenderse al norte y este de la plataforma. Asimismo, la sección aterrazada de la plaza se ubica en el lado oeste, a diferencia de los dos otros edificios. La plataforma principal de Pañamarca presentaba su acceso en el lado oeste, a través de una rampa en zigzag (Bonavia \& Makowski, 1999) precedida por una plaza relativamente pequeña, en contraposición a una amplia plaza cercada casi cuadrangular ubicada junto al lado norte de la plataforma. Huancaco, a pesar de compartir un asiento geográfico similar a Huaca de la Luna, se caracterizaba por una multiplicidad de patios y recintos donde actividades domésticas y públicas de la élite local se hacen fuertemente evidentes (Bourget, 2003). 
Es válido preguntarse qué actividades pudieron alcanzar un grado notable de repercusión social para merecer la recreación de su continente arquitectónico. Todavía no se han caracterizado las actividades desarrolladas en la plaza frontal de Plataforma $A^{2}$, pero la presentación de datos ya evaluables para Plaza 1 (Aguilar et al., 1999; Armas et al., 2003) permite considerar rasgos específicos del empleo de este tipo de espacio en Huaca de la Luna.

\section{CONCENTRACIÓN DE GRUPOS HUMANOS}

La función como área de concentración masiva de público adquiere un carácter crucial para entender el rol de este tipo de espacio arquitectónico. Su definición atraviesa la coyuntura de la falta de evidencias contextuales de concentraciones humanas, lo cual conlleva a que el análisis de esta función implique aproximarnos a las nociones de escala del espacio personal lo cual, tal como veremos luego, no debe ser tomado como un sencillo juego de proporción entre individuos y espacio físico.

La Plaza 1 puede ser dividida entre un área llana $\left(8700 \mathrm{~m}^{2}\right)$ y el sector aterrazado oriental $\left(3470 \mathrm{~m}^{2}\right)$, espacios que adquieren arreglos morfológicos distintos y posiblemente formas también disímiles de concentración de grupos humanos. Las terrazas presentaban áreas que podían canalizar linealmente el tráfico pedestre (corredores y rampas), asimismo los recintos identificados hasta ahora parecen concebidos para formas no masivas de funcionalidad. En contraste, el área llana se extendía desde al acceso a la plaza hasta la plataforma y lateralmente vinculaba al sector oriental con pequeñas terrazas junto al muro perimetral oeste, el carácter abierto y la extensión de esta área la evidenciarían como la verdadera zona factible de haber albergado a grandes cantidades de público.

El uso de valores promedio de espacio personal empleados en análisis de espacios públicos del Horizonte Temprano (Burger, 1987), poblados en la Amazonia o el sitio Inca de Ollantaytambo (Moore, 1996) puede arrojar cifras bastante diferentes de la capacidad humana en la Plaza 1. Considerando estimados de $0,46 \mathrm{~m}^{2}, 3,6 \mathrm{~m}^{2}$, y $21,6 \mathrm{~m}^{2}$ por persona, la plaza pudo dar cabida a 26 467, 3381 ó 563 individuos respectivamente. Estas cantidades solo reflejan la variabilidad en la capacidad humana de este tipo de espacio ceremonial. En el caso del área llana es probable que ocurriera una división horizontal en la densidad del uso del espacio según el tipo de evento y el área enfocada por los concurrentes (Plataforma I, terrazas o el propio ingreso a la plaza).

Aún no se ha excavado el área central de la plaza, pero es del todo probable que en ella ocurriera la mayor densidad de concurrentes al constituirse en el principal punto de tránsito hacia otros sectores del conjunto y un espacio adecuado para apreciar el frontis de la Plataforma I. La presencia de pequeñas terrazas junto al muro perimetral oeste y de recintos decorados bajo la plataforma abiertos directamente hacia la plaza, podría indicar que la función pública de este sector incorporaba tanto momentos de mayor cercanía entre oficiantes y concurrentes como formas de comunicación indirecta y simbólica a través de la observación de iconografía mural y actividades alejadas. El contraste entre las áreas llanas y áreas como el ingreso a la plaza o el Recinto 2, indicarían un énfasis en diversificar el uso social del espacio, demarcando parámetros de conducta inherentes a actividades como el acto de ingreso al templo o la proximidad entre el público y funcionarios.

\section{ACTIVIDADES PÚBLICAS VS. PRIVADAS}

El Recinto 2 (Aguilar et al., 1999; Armas et al., 2003) es un claro ejemplo de la división del espacio de esta plaza entre áreas realmente públicas y sectores privativos. El recinto (de $115 \mathrm{~m}^{2}$,

2 La plataforma A ha sido investigada recientemente por el Proyecto Arqueológoco Galindo dirigido por Gregory Lockard de la Universidad de New Mexico, este nuevo estudio brindará sin duda valiosos datos sobre la cronología y función de este edificio y el asentamiento de Galindo. 
delimitado por muros de 2,5 m de altura) era accedido por un único vano en el lado norte, luego un corredor indirecto conducía a un patio con banqueta de rampa central, similar a los tablados Moche $\mathrm{V}$ en Galindo. El corredor estaba definido por un muro en $\mathrm{L}$, de solo 1,30 $\mathrm{m}$ de altura y con cabecera de sección trapezoidal, el resto de muros al interior del recinto eran delgados y bajos, con la excepción de un ambiente en la esquina sureste. La organización del espacio y la elevación de los muros evidencian que el tránsito en el Recinto 2 se habría adecuado a un esquema de desplazamiento inicialmente compartimentalizado y luego axial ante una estructura jerárquica, pero también que este orden no excluía una comunicación visual distinta a aquella configurada por la arquitectura.

La funcionalidad de este recinto habría incluido actividades de presentación y contacto social entre una cantidad limitada de concurrentes a la plaza y jerarcas u oficiantes, posiblemente en forma similar a lo mostrado en iconografía cerámica de la Fase IV (Donnan \& McClelland, 1999). Este caso sugiere que las plazas frontales podían incluir sectores destinados a brindar privacidad a un segmento menor de asistentes, en áreas físicamente cerradas y funcionalmente vinculadas a prácticas de interacción social donde la comunicación directa y/o la proximidad de los individuos jugaba un rol importante (Moore, 1996: 153-155). Ello se contraponía a los probables parámetros de interacción humana en áreas llanas de las plazas, donde la comunicación estaba limitada por la amplitud del espacio abierto, dando paso a formas distintas de perceptibilidad de discursos.

\section{PRIMER ESCENARIO EN EL SISTEMA RITUAL DEL TEMPLO}

La probable función como área para el desfile de combatientes y prisioneros está indicada por la presencia de segmentos iconográficos del complejo religioso y sacrificial Moche en el frontis de la Plataforma I, pero adquiere un carácter peculiar pues depende también de la evidencia iconográfica y contextual en áreas accedidas desde la Plaza 1. Este uso hipotético de la plaza no ha podido ser contrastado con evidencias distintas a las artísticas, pero es completamente factible el uso de este espacio por los observadores de actividades en el lado noreste de la Plataforma I, propuesto por Uceda (2001) como el escenario de presentación de copas por altos dignatarios, lo cual convertiría a la Plaza 1 en parte integral de uno de los eventos finales del ceremonial en el complejo.

\section{CONTINUIDAD Y CAMBIO EN LA ARQUITECTURA CEREMONIAL MOCHE IV Y V DEL VALLE DE MOCHE}

Un esquema de continuidad e innovación conjuntos en el diseño de la Plataforma A de Galindo como reminiscencia del conjunto de Huaca de la Luna conlleva dos aspectos explícitos: 1) la configuración de la Plaza 1 de Huaca de la Luna sirvió de modelo para la planificación de la gran plaza asociada a la Plataforma A de Galindo, y 2) las diferencias volumétricas y cualitativas entre las plataformas asociadas a estas plazas denotarían una serie de cambios tanto en la planificación arquitectónica como en el manejo del rol ideológico de la arquitectura pública.

Aproximarse al significado de esta variabilidad en dimensión, forma y acabado implica examinar dos aspectos que habrían incidido en su planificación: la reorganización del manejo de recursos controlados por las élites Moche, y un proceso de índole ideológica asociado a las transformaciones de las estructuras políticas Moche en el valle del mismo nombre.

\section{CAMBIOS ECONÓMICOS, IDEOLOGÍA Y EL MANEJO DE ARQUITECTURA PÚBLICA}

La evaluación tradicional sobre los cambios en la economía regional durante la transición Moche IV-V descansa sobre la noción del mantenimiento previo de un orden sociopolítico a través del cual los recursos de gran parte de la sección meridional de la costa norte fluían hacia el valle de Moche 
y sus líderes, particularmente durante la Fase IV (Bawden, 2001: 291; Chapdelaine, 2003). Los cambios en la interacción entre este valle y el área entre Virú y Huarmey son considerados factores causales de una reducción en la cantidad de bienes que se dirigían al sitio Moche. La conclusión más resaltante de este postulado es que los líderes Moche en el valle homónimo y especialmente los del sitio Moche habrían visto una drástica merma en su capacidad de manejo de recursos y facultades de redistribuir los mismos a fines de la Fase IV (vg. 600 d. C.), y que el nuevo orden sociopolítico afiliado al estilo Moche $\mathrm{V}$ reorganizó su base económica al atraer al medio urbano a grupos de bajo status o procedentes del medio rural, dirigiendo la mayoría de sus recursos hacia obras de función secular. La evidencia más segura en este panorama es la reducción del área de dominio Moche Sureño a los valles de Moche y Chicama, con una notoria disminución y eventual pérdida de materiales de la Fase IV en valles como el de Santa, donde este estilo era representativo de una fuerte actividad cultural y política Moche (Chapdelaine \& Pimentel, 2003).

Los datos sobre la extensión del área controlada por Galindo aún son escasos. En el valle de Chicama existen sitios que han producido materiales de la Fase $\mathrm{V}$ con el estilo geométrico de Galindo (Gutiérrez, 1997), pero también se han documentado materiales afines a la producción artística del valle de Jequetepeque (Franco et al., 2003). Chapdelaine (2000: 137-138) ha sugerido que parte del margen sur del valle bajo de Moche (donde los materiales de la Fase $\mathrm{V}$ son escasos) pudo continuar bajo el dominio de Huacas de Moche y de pobladores produciendo cerámica Moche IV posiblemente hasta $700 \mathrm{~d}$. C.

Una disminución de ingresos económicos a las élites Moche en el valle de Moche durante los inicios del Horizonte Medio pudo motivar la reestructuración de los sistemas de movilización de fuerzas laborales, particularmente si las grandes construcciones eran logradas mediante la participación de múltiples comunidades bajo una organización de tributación laboral (Hasting \& Moseley, 1975) controlada y auspiciada por grupos de alta jerarquía. Sin embargo, las dimensiones de la asociada a la Plataforma A no reflejan reducción en comparación a Huacas de Moche y en particular a la plaza frontal de Huaca de la Luna. Eso estaría en correspondencia a que la construcción de una plaza cercada no exige la cantidad de esfuerzo humano e inversión económica que demanda una plataforma. La volumetría del sector oriental en la Plaza 1 evidencia que la inversión de materiales en su construcción fue mucho menor a la necesaria en la Plataforma I. Mientras que la construcción del Edificio A habría requerido $42993 \mathrm{~m}^{3}$ de adobe (Uceda \& Tufinio, 2003: 217), las terrazas de la Plaza 1 alcanzaron un volumen conjunto de $14300 \mathrm{~m}^{3}$ de adobe. En 1999 se observó que al menos la segunda terraza presenta una superposición de rellenos alternados con pisos de barro, indicando que su masividad era el resultado de sucesivas adiciones arquitectónicas. Es posible que el volumen total de rellenos de adobe en el sector este de la Plaza 1 durante la etapa constructiva contemporánea al Edificio A no sobrepasara los $10000 \mathrm{~m}^{3}$. Los moche de Galindo pudieron invertir cantidades relativamente menores de excedentes y mano de obra para auspiciar la creación de una gran plaza que precediera a una plataforma relativamente menor con relación a edificios más tempranos y de larga secuencia constructiva en Huacas de Moche, o contemporáneos como Huaca Fortaleza en Pampa Grande.

El énfasis puesto en la reiteración de elementos tradicionales de planificación arquitectónica en la plaza frontal de la Plataforma A pondría en evidencia la voluntad por parte de sus autoridades religiosas de mantener un vínculo con la tradición ceremonial y política previa, específicamente en la organización del espacio destinado a dar cabida a multitudes de asistentes a actos ceremoniales públicos. Pero esta posibilidad contrasta con el carácter marcadamente distinto entre las plataformas adjuntas a esos espacios.

Un concepto clave para entender el proceso de crecimiento de algunos edificios ceremoniales que antecedieron a los erigidos en la Fase Moche $V$ es el proceso denominado por Uceda y Canziani (1998: 157-158) «regeneración del templo», que implicaba eventos cíclicos de enterramiento y reedición de construcciones, conduciendo a que plataformas de dimensiones modestas alcanzaran progresivamente proporciones mayores. ¿De haber continuado la ideología y la política Moche prevaleciendo en Galindo, la Plataforma A habría experimentado un proceso semejante al de 
anteriores edificaciones ceremoniales? La cronología de la ocupación Moche de Galindo y el conjunto de Plataforma A implica directamente esta interrogante. Si las actividades Moche en Galindo no se prolongaron más allá de 750 d. C., como sugieren los fechados publicados para el sitio (Conrad, 1974; Bawden, 1994: 409), este proceso cíclico no habría ocurrido.

Las restricciones en el manejo de excedentes productivos habrían conllevado a que una entidad como la de Galindo retornara a la situación que pudo haber experimentado una organización sociopolítica durante las fases Moche más tempranas, en las cuales la población de un valle no habría usufructuado directamente la producción de áreas vecinas, debido a la fragmentación política imperante para estas fechas (Topic, 1982: 284; Shimada, 1994a: 377). A partir de esta coyuntura, los jerarcas Moche $V$ en el valle de Moche no solo debieron innovar sus estructuras políticas (acto evidenciado en la disposición de las cercaduras al centro del poblado), también pudieron manipular los preceptos ideológicos de «regeneración del templo» para afrontar la menor posibilidad de expendio de recursos en la construcción de grandes plataformas y propiciar la fundación de una de tamaño similar a versiones tempranas de este tipo de arquitectura ceremonial. De corresponder a un único evento constructivo el volumen estimable en $32500 \mathrm{~m}^{3}$ de relleno en la Plataforma A, sería evidente que la inversión de recursos y mano de obra en esta construcción cubrió nada menos que las tres cuartas partes de los $42933 \mathrm{~m}^{3}$ demandados por el Edificio A de Huaca de la Luna (Uceda \& Tufinio, 2003).

\section{SIGNIFICADO DE LA CORRELACIÓN DE CRONOLOGÍAS Y ESPACIOS ARQUITECTÓNICOS}

La relación temporal entre Galindo y Huacas de Moche ha adquirido un nuevo enfoque en los últimos años. La mayoría de fechas radiocarbónicas para el sitio Moche asociadas a materiales de la Fase IV, sitúa la ocupación vinculada a esta fase estilística entre mediados del siglo $\mathrm{V}$ (vg. 450 d. C.) y mediados del siglo VIII (vg. 750 d. C.) (Chapdelaine, 2002: 78-79). Para Galindo se señala una ocupación iniciada tras las fechas anteriormente manejadas para el abandono del sitio Moche alrededor del 550 - 600 d. C. o durante los inicios del siglo VII (Conrad, 1974; Bawden, 1996). Esta superposición de fechados ha conducido al postulamiento de una probable coetaneidad entre la ocupación final del sitio de Huacas de Moche y el desarrollo del cercano asentamiento Moche V en Galindo (Chapdelaine, 2000; 2002: 77).

Las similitudes formales entre las plazas de mayor extensión en la Plataforma A y Huaca de la Luna pueden ser apreciadas como una influencia directa del antiguo centro religioso en el nuevo espacio ceremonial de Galindo. Alternativamente, la semejanza formal puede ser vista como un caso de revitalización o reavivamiento de un modelo arquitectónico. Ambas posiciones deberán ser evaluadas en el futuro, pero es posible asumir que el proceso que condujo a las transformaciones políticas, económicas e ideológicas en el valle de Moche fue suficientemente complejo, y acaso multifacético, como para reducirlo a un modelo rígido de cambio cultural. La organización sociopolítica del sitio al pie de Cerro Blanco tras alcanzar su apogeo a mediados de la Fase IV pudo haber experimentado un proceso de desarticulación interna que originó la aparición en el valle de nuevas entidades políticas en lo que fuera un área centralizada (Marcus, 1998). Estas entidades pudieron coexistir durante algunas generaciones en el valle de Moche alrededor de sendos centros de poder o asentamientos principales, creando una situación que no había ocurrido dentro del valle en al menos los cuatro siglos precedentes.

La contemporaneidad entre la ocupación final del sitio Moche y la ocupación de Galindo abre la posibilidad de influencia del modelo vigente de Huaca de la Luna sobre la Plataforma A de Galindo. El prestigio de Huaca de la Luna pudo incidir directamente en la concepción del nuevo templo en Galindo, aún cuando los líderes en ese asentamiento seleccionarán qué elementos arquitectónicos podrían y deberían replicar. Los aspectos formales de la Plaza 1 habrían sido los elegidos para este proyecto, específicamente en lo referente al diseño del sector oriental, 
donde se encontraban estructuras que servían para canalizar el tránsito y crear distintos niveles de proximidad humana. La plaza frontal de Plataforma A de Galindo habría sido concebida teniendo como referente inmediato a la plaza mayor de Huaca de la Luna, la cual conservaba su rol de eje en las ceremonias y rituales religiosos del sitio Moche.

Aunque carecemos de una datación exacta para el cese del funcionamiento de Huaca de la Luna, el registro de la clausura del vano de acceso a la Plaza 1 puede aportar una evidencia sobre este momento. La construcción del sello, y su enlucido solo en el paramento exterior, pudo ser obra de los ocupantes Moche más tardíos en el sitio. Uceda y Tufinio (2003: 215) han propuesto una reorientación de la actividad pública en la urbe hacia Plataforma III y la última etapa constructiva de Huaca del Sol, que pasaron a ser los ejes de la vida ritual y secular del asentamiento. Al parecer, la Plataforma I y las edificaciones directamente asociadas no estuvieron en funcionamiento hasta el ocaso del sitio.

La coetaneidad entre la ocupación en Galindo y la ocupación del sitio Moche que no incluía a la Plataforma I ni estructuras asociadas, implicaría que no existió influencia directa de Huaca de la Luna sobre la Plataforma A de Galindo, puesto que el funcionamiento de la sección más antigua en el primer complejo debió cesar antes que el sitio Moche fuera totalmente abandonado por sus últimos ocupantes con identidad Moche. Es factible proponer el reavivamiento de rasgos arquitectónicos y funcionales de Huaca de la Luna en el conjunto de la Plataforma A de Galindo, pero aún debemos esclarecer qué aspecto específico habría adquirido este hecho. Stone-Miller (1993: 34-35) al examinar el reavivamiento como medio de cambio estilístico, señala que puede adoptar modos suficientemente distintos como para merecer ser identificados y examinados cuidadosamente. No obstante, la revitalización puede ser conceptualizada como una fuente de cambio cultural que ocurre cuando los miembros de una población perciben el decaimiento y eventual peligro de colapso de su cultura, emergiendo en ese contexto líderes que revitalizan viejos símbolos de prestigio o éxito sancionados por la tradición y los emplean para fortalecer su sociedad, desde la égida de su mandato (Sharer \& Ashmore, 1979: 495-496).

La construcción del conjunto de Plataforma A de Galindo pudo aparecer como la revitalización por reelaboración de un modelo tradicional de espacio público y sacro. El diseño de sectores específicos de Plaza 1 (funcionalmente ya no vigente) fue retomado por los líderes del proyecto constructivo de Plataforma A, quienes decidieron modificar el diseño y forma del edificio platafórmico y otros espacios adyacentes. La reiteración de aspectos formales entre las plazas implicaría un mantenimiento en la memoria de diversos niveles socioeconómicos Moche en el valle homónimo de la importancia de estos espacios para la interacción ceremonial masiva.

Fenómenos de reavivamiento ya han sido referidos para la revitalización de motivos iconográficos: Cupisnique en el arte Salinar (Elera, 1997: 195) y Moche (Campana \& Morales, 1997). En un contexto de referencia más amplio, el uso renovado de antiguos modelos arquitectónicos también ha sido propuesto para casos en Mesoamérica. Habría ocurrido en Tikal, a fines del siglo VII d. C., cuando un gobernante logró consolidar el poder de esta metrópoli a través de la guerra, la proclamación de relaciones genealógicas pretéritas, y el reavivamiento de íconos y modelos arquitectónicos antiguos (Sharer \& Ashmore, 1979: 496). El segundo caso Maya Clásico Tardío ocurrió en El Naranjo, donde un gobernante logró reproducir los arreglos triádicos de plataformas del Preclásico Tardío al reconstruir su ciudad, que había sido sometida a privaciones en el juego político regional (Schele \& Freidel, 1999: 258).

La similitud entre las plazas mayores en Huaca de la Luna y la Plataforma A evidencian continuidad dentro del marco de la concepción formal de los espacios públicos Moche, pero sería erróneo pensar que algunos gobernantes en Galindo recayeron exclusivamente sobre la ideología y simbolismo de sus predecesores en Huacas de Moche. La probable recreación de un espacio público ceremonial y tradicional en la plaza mayor de Plataforma A de Galindo indicaría la aceptación de un modelo de espacio sacralizado y sancionado por la tradición, pero cuyo uso debía adaptarse a la coyuntura particular del desarrollo urbano de Galindo. 


\section{COMENTARIOS FINALES}

Las diferencias de magnitud entre el sitio de Huacas de Moche y el resto de asentamientos en el valle de Moche durante el Intermedio Temprano (Billman, 1996) evidencian de manera contundente la ausencia de sitios que pudieran rivalizar la hegemonía de Huacas de Moche. Sin embargo, Galindo constituyó un asentamiento tan extenso y complejo como para ser un válido parangón al sitio Moche.

¿En qué forma el surgimiento de Galindo pudo contribuir directamente a acelerar la decadencia de Huacas de Moche? La constitución de este nuevo centro de poder político y religioso pudo contribuir a la desarticulación de la entidad centralizada en Moche, al competir con la tradicional metrópoli en su propia área nuclear. No obstante, es necesario preguntarse si este escenario no habría podido motivar un refortalecimiento del sitio Moche, en lugar de su eventual colapso como centro urbano. Las evidencias para postular que Galindo confrontó la supremacía de Huacas de Moche son escasas, pero la escasa interacción perceptible en la cultura material mueble de sus élites podría ser tomada en cuenta dentro de ésta perspectiva3.

Topic (1982: 273) y Chapdelaine (2000: 127; 2002: 77) fueron explícitos al señalar la ausencia de materiales de la Fase $V$ en su registro de diversos sectores del área central del sitio Moche. Ante esta situación la repercusión del rol de los espacios ceremoniales de Huaca de la Luna en algunas edificaciones de Galindo, y posiblemente también de elementos de la cultura material y espiritual del viejo asentamiento en aquel nuevo, deberá evaluarse para determinar la naturaleza de la interacción entre estos dos centros Moche en el valle del mismo nombre.

Varias generaciones de arqueólogos han enfocado la transición entre las Fases IV y V en la sección meridional de la costa norte como un proceso de reemplazo de formas tradicionales de gobierno e ideología por nuevas formas de conducta social que, aunque enraizadas en las instituciones sociales regionales y andinas innovaron drásticamente el panorama sociopolítico Moche. En la actualidad, gracias al constante aumento de información, podemos examinar cómo este proceso habría adquirido un carácter no solo complejo y dinámico, también podemos vislumbrar cómo la consolidación de las instituciones políticas estatales estaba inherentemente asociada a ensayos de cohesión social. En la evolución sociopolítica del valle de Moche, las entidades Moche que fomentaron el urbanismo y la centralización ciertamente fueron dirigidas por una clase política que no dependía totalmente de las reglas sancionadas por la tradición y las relaciones ancestrales de parentesco para desarrollar sus propios intereses (Bawden, 1994; 2001). Pero en este proceso también se incorporaban la creación y mantenimiento de ambientes físicos que permitían una participación social masiva, pero inherentemente diversificada y selectiva, en áreas específicas de la puesta en práctica ideológica del gobierno.

Sobre nuestra propuesta esperamos contrastaciones futuras que permitan ampliar y eventualmente modificar los puntos aquí establecidos. Sin embargo, creemos que existen nuevos elementos de juicio para apreciar la evidencia brindada por la arquitectura monumental Moche, la cual ofrece un sobresaliente reflejo del proceso cultural de las poblaciones prehispánicas de la costa norte.

\section{Agradecimientos}

El autor desea expresar su agradecimiento a los directores del Proyecto Arqueológico Huaca de la Luna, Santiago Uceda y Ricardo Morales, por su enorme apoyo al grupo de estudiantes que en 1999 realizo excavaciones en la Plaza 1, Santiago Uceda brindo posteriormente su aliento para terminar la redacción de este trabajo. Helène Bernier realizo la traducción al ingles y francés del resumen del artículo. Asimismo deseo reconocer las críticas y sugerencias de Claude Chapdelaine y Carol Mackey sobre varias secciones del mismo.

3 La escasez de materiales típicamente Moche $V$ en el sitio de Huacas del Sol y de la Luna no solo implicaría una diferenciación estilística, las instituciones comerciales encargadas de los mecanismos de interacción económica no habrían incluído el intercambio de artículos estilísticamente diagnósticos (cerámica fina p. ej.), esta situación entraña obvios factores políticos y económicos entre asentamientos tan próximos (Blanton, 1998: 138). 


\section{Referencias citadas}

AGUILAR, J., BELLODAS, R., GAMBOA, J., HARO, O. \& REGALADO, D., 1999 - Estudio Arquitectónico de la Plaza 1 de Huaca de la Luna, Valle de Moche. Informe de prácticas pre-profesionales. Universidad Nacional de Trujillo.

ALVA, W. \& DONNAN, C., 1993 - Royal Tombs of Sipan, 229 p.; Los Angeles: University of California, Fowler Museum of Cultural History.

ARMAS, J., AGUILAR, J., BELLODAS, R., GAMBOA, J., HARO, O. \& REGALADO, D., 2003 - Excavaciones en la Plaza 1 y el Frontis Norte de Plataforma I de Huaca de la Luna. In: Investigaciones en la Huaca de la Luna 1998-1999 (Uceda, S., Mujica, E. \& Morales, R., eds.): 51-94; Trujillo: Universidad Nacional de Trujillo, Facultad de Ciencias Sociales. Proyecto Arqueológico Huaca de la Luna.

BAWDEN, G., 1977 - Galindo and the nature of the Middle Horizon in the Northern Coastal Peru; Cambridge: Harvard University. Tesis de doctorado.

BAWDEN, G., 1982 - Galindo: a study in cultural transition during the Middle Horizon. In: Chan Chan Andean Desert City (Moseley, M. \& Day, K., eds.): 285-320; Albuquerque: University of New Mexico Press.

BAWDEN, G., 1983 - Cultural reconstitutions in the Late Moche Period: a case study in multi-dimensional stylistic analisis. In: Civilization in the Ancient Americas: Essays in honor of Gordon R. Willey (Leventhal, R. \& Kolata, A., eds.): 211-235; Albuquerque: University of Mexico Press.

BAWDEN, G., 1994 - La paradoja estructural, la cultura Moche como ideología política. In: Moche propuestas y perspectivas (Mujica, E. \& Uceda, S., eds.): 389-412; Lima: IFEA - FOMCIENCIAS - Universidad Nacional de Trujillo. Actas del Primer Coloquio sobre la cultura Moche, Trujillo 12 al 16 de abril de 1993. Travaux de l'Institut Français d'Études Andines, 79.

BAWDEN, G., 1996 - The Moche, 375 p.; London: Blackwell

BAWDEN, G., 2001 - The symbols of Late Moche social transformation. In: Moche Art and Archaeology in Ancient Peru (Pillsbury, J., ed.): 285- 305; Washington D. C.: Center for Advanced Studies in the Visual Arts, National Gallery of Art.

BILLMAN, B., 1996 - The evolution of Prehistoric Political Organization on the Moche Valley, Peru; Santa Barbara: Department of Anthropology, University of California. Tesis de doctorado.

BLANTON, R., 1998 - Beyond Centralization: Steps toward a theory of egalitarian behavior in Archaic States. In: Archaic States (Feinmann, G. \& Marcus, J., eds.): 135- 172; Santa Fe, Nuevo Mexico: School of American Research Press.

BONAVIA, D. \& MAKOWSKI, K., 1999 - Las pinturas murales de Pañamarca: un santuario Mochica en el olvido. Iconos, 2: 40-54; Lima: Instituto Yachay Wasi.

BOURGET, S., 1998 - Excavaciones en la Plaza 3A y en la Plataforma II de Huaca de la Luna durante 1996. In: Investigaciones en Huaca de la Luna 1996 (Uceda, S., Mujica, E. \& Morales, R., eds.): 43-64; Lima: Proyecto Arqueológico Huacas del Sol y la Luna-Facultad de Ciencias Sociales, Universidad Nacional de Trujillo.

BOURGET, S., 2003 - Somos diferentes: dinámica ocupacional del sitio Castillo de Huancaco, valle de Virú. In: Moche hacia el final del milenio (Uceda, S. \& Mujica, E., eds.): 245-268. Fondo Editorial de la Pontificia Universidad Católica del Perú - Universidad Nacional de Trujillo.

BURGER, R., 1987 - The U-shaped pyramid complex, Cardal, Peru. National Geographic Research, 3: 363-375. 
Organización de los espacios arquitectónicos de las Huacas de la Luna y Galindo

CAMPANA, C. \& MORALES, R., 1997 - Historia de una deidad Mochica, 120 p.; Lima: Editorial A\&B.

CASTILLO, L. J., 2001 - La presencia Wari en San José de Moro. Boletín de Arqueología PUCP, 4: 143-180; Lima: Fondo Editorial de la Pontificia Universidad Católica del Perú.

CASTILLO, L. J. \& DONNAN, C., 1994 - Los Mochicas del Norte y los Mochicas del Sur. In: Vicus (Makowski, K. et al., eds.): 143-181; Lima: Banco de Crédito del Perú. Colección Arte y Tesoros del Perú.

CHAPDELAINE, C., 2000 - Struggling for survival: the urban class of the Huacas de Moche site, North Coast of Peru. In: Natural Disasters and the Archaeology of Human Response (Bawden, G. \& Reycraft, R., eds.): 121-142; Albuquerque: University of Mexico Press. Maxwell Museum of Anthropology. Anthropological Papers Number 7.

CHAPDELAINE, C., 2001 - The growing power of a Moche urban class. In: Moche Art and Archaeology in Ancient Peru (Pillsbury, J., ed.); Washington D. C.: National Gallery of Art.

CHAPDELAINE, C., 2002 - Out in the streets of Moche. Urbanism and sociopolitical organization at a Moche IV urban center. In: Andean Archaeology I (Isbell, W. \& Silverman, H., eds.): 53-88; New York: Kluver Academic Press-Plenum Publishers.

CHAPDELAINE, C., 2003 - La ciudad de Moche: urbanismo y Estado. In: Moche hacia el final del milenio (Uceda, S. \& Mujica, E., eds.): 2437-285; Lima: Fondo Editorial de la Pontificia Universidad Católica del Perú-Universidad Nacional de Trujillo.

CHAPDELAINE, C. \& PIMENTEL V., 2003 - Un tejido único Moche III del sitio Castillo de Santa: una escena de cosecha de yuca. Bulletin de I'Institut Français d'Études Andines, 32 (1): 23-50; Lima.

CHAUCHAT, C., 2000 - Grande Cité de Moche. Découvertes dans la mystérieuse. Archéologia, 368: 32-41; Dijon: Editions Faton.

CONRAD, G., 1974 - Burials platforms and related structures on the North Coast of Peru: Some social and political implications; Cambridge: Department of Anthropology, Harvard University. Tesis de doctorado.

CORDY- COLLINS, A., 1992 - Archaism or continuing tradition: The Decapitation theme in Cupisnique and Moche iconography. Latin American Antiquity, 3 (3): 206-292; Washington D. C.: Society for American Archaeology.

DEMARAIS, E., CASTILLO, L. J. \& EARLE, T., 1996 - Ideology, materialization and power strategies. Current Anthropology, 37 (1): 15-31; Chicago: Wenner-Green Foundations for Anthopological Research.

DILLEHAY, T., 2001 - Town and country in Late Moche times: a view from two Northern valleys. In: Moche Art and Archaeology in Ancient Peru (Pillsbury, J., ed.): 259-283; Washington D. C.: National Gallery of Art.

DONNAN, C., 1968 - An association of Middle Horizon Epoch 2A: Specimens from the Chicama Valley, Peru. Nawpa Pacha, 6: 15-18; Berkeley: Institute of Andean Studies.

DONNAN, C., 2003 - Tumbas con entierros en miniatura: un nuevo tipo funerario Moche. In: Moche hacia el final del milenio (Uceda, S. \& Mujica, E., eds.): 43-78; Lima: Fondo Editorial de la Pontificia Universidad Católica del Perú-Universidad Nacional de Trujillo.

DONNAN, C. \& MCCLELLAND, D., 1999 - Moche Fineline Paintings, its evolutions and its artists. Fowler Museum of Cultural History; Los Angeles: University of California at Los Angeles. 
ELERA, C., 1997 - Cupisnique y Salinar: algunas reflexiones preliminares. Arquitectura y civilización en los Andes Prehispánicos (Bonnier, E. \& Bischof, H., eds.): 176-201; Mannheim: Sociedad Arqueológica Peruano-Alemana y Reiss Museum Mannheim. Archaeologica Peruana, 2.

FRANCO, R., GALVEZ, C. \& VASQUEZ, S., 1994 - Arquitectura y decoración Mochica en la Huaca Cao Viejo, complejo El Brujo: resultados preliminaries. In: Moche: propuestas y perspectives (Uceda, S. \& Mujica, E., eds.): 147-180. Lima: IFEAFOMCIENCIAS-Universidad Nacional de Trujillo. Actas del primer Coloquio sobre la Cultura Moche. Travaux de I'Institut Français d'Études Andines, 79.

FRANCO, R., GALVEZ, C. \& VASQUEZ, S., 2003 - Modelo, función y cronología de la Huaca Cao Viejo, Complejo El Brujo. In: Moche al final del milenio (Uceda, S. \& Mújica, E., eds.): 43-78; Lima: Fondo Editorial de la Pontificia Universidad Católica del Perú-Universidad Nacional de Trujillo.

GUTIÉRREZ, B., 1997 - Licapa II, un asentamiento urbano-ceremoniales el Valle de Chicama, observaciones preliminares. Revista del Museo de Arqueología, Antropología e Historia, 7: 131-156; Lima: Facultad de Ciencias Sociales, Universidad Nacional de Trujillo.

HAAS, J., 1985 - Excavation on Huaca Grande: An initial view of the elite at Pampa Grande, Peru. Journal of Field Archaeology, 12 (4): 391-409; Cambridge.

HASTINGS, C. \& MOSELEY, M., 1975 - The adobes of Huacas del Sol and Huaca de la Luna. American Antiquity, 40: 196-203.

LARCO, R., 1948 - Cronología Arqueológica del Norte del Perú, 87 p.; Buenos Aires: Sociedad Geográfica Americana.

MACKEY, C. \& HASTINGS, C., 1982 - Moche mural from the Huaca de la Luna. In: Precolumbian Art History Selected Readings (Cordy-Collins, A., ed.): 293-312; Palo Alto: Peeks Publications.

MAKOWSKI, K., 2003 - La deidad suprema en la iconografía Mochica: ¿cómo definirla? In: Moche al final del milenio (Uceda, S. \& Mujica, E., eds.): 343-382; Lima: Fondo Editorial de la Pontificia Universidad Católica del Perú-Universidad Nacional de Trujillo

MARCUS, J., 1998 - The peaks and valleys of Ancient States: an extension of the Dynamical Model. In: Archaic States (Feinmann, G. \& Marcus, J., eds.): 59-94; Santa Fe, Nuevo Mexico: School of American Research Press.

MENZEL, D., 1964 - Style and Time in the Middle Horizon. Nawpa Pacha, 2: 1-105; Berkeley: Institute of Andean Studies.

MOORE, J., 1996 - Architecture and power in the Ancient Andes. The archaeology of Public Buildings, 255 p.; Cambridge: Cambridge University Press. New Studies in Archaeology.

MOSELEY, M., 1992 - The Incas and their Ancestors, 272 p.; Londres: Thames and Hudson.

PIMENTEL, V. \& ALVAREZ, G., 2000 - Relieves policromos en la Plataforma Funeraria Uhle. In: Investigaciones en la Huaca de la Luna 1997 (Uceda, S., Mujica, E. \& Morales, R., eds.): 182- 203; Trujillo: Facultad de Ciencias Sociales. Universidad Nacional de Trujillo. Proyecto Arqueológico Huaca de la Luna.

REINDEL, M., 1993 - Monumentale Lehmarchitektur an der Nordküste Perus: Eine repräsentative Untersuchung nach-formativer Großbauten vom Lambayeque bis zum Virú-Tal, 471 p.; Bonn: Bonner Amerikanistische Studies. Bass 22.

SCHAEDEL, R., 1951 - Major ceremonial and population centers in the Northern Peru. In: The civilization of Ancient America. Selected Papers of the $29^{\text {th }}$ International Congress of Americanist: 232-234; Soltax Editions. 
Organización de los espacios arquitectónicos de las Huacas de la Luna y Galindo

SCHELE, L. \& FREIDEL, D., 1999 - Un bosque de reyes. México D. F.: Fondo de Cultura Económica.

SHARER, R. \& ASHMORE, W., 1979 - Fundaments of Archaelogy. California: The Benjamin/ Cummings Publishings, Inc. Menlo Park.

SHIMADA, I., 1994a - Los modelos de organización sociopolítica de la cultura Moche. In: Moche propuestas y perspectivas (Mujica, E. \& Uceda, S., eds.): 359-387; Lima: IFEA-FOMCIENCIAS-Universidad Nacional de Trujillo. Actas del Primer Coloquio sobre la cultura Moche, Trujillo 12 al 16 de abril de 1993. Travaux de I'Institut Français d'Études Andines, 79.

SHIMADA, I., 1994b - Pampa Grande and the Mochica Culture, 323 p.; Austin: University of Texas Press.

STONE-MILLER, R., 1993 - An overview of «Horizon» and «Horizon Style» in the study of Ancient American Objects. Latin American Horizons (Rice, D. S., ed.): 15-39; Washington D. C.: Dumbarton Oaks.

TELLO, R., 1998 - Los conjuntos arquitectónicos 8, 17, 18 y 19 del centro urbano Moche. In: Investigaciones en la Huaca de la Luna 1996 (Uceda, S., Mujica, E. \& Morales, R., eds.): 117-135; Trujillo: Facultad de Ciencias Sociales, Universidad Nacional de Trujillo. Proyecto Arqueológico Huaca de la Luna.

TOPIC, T., 1982 - The Early Intermediate Period and its legacy. In: Chan Chan Andean Desert City (Moseley, M. \& Day, K., eds.): 255-284; Albuquerque: University of New Mexico Press.

UCEDA, S., 2001 - Investigations at Huaca de la Luna, Moche Valey: An example of Moche religious architecture. In: Moche Art and Archaeology (Pillsbury, J., ed.): 47-67; Washington D. C.: National Gallery of Art.

UCEDA, S. \& CANZIANI, J., 1993 - Evidencias de grandes precipitaciones en diversas etapas constructivas de la Huaca de la Luna, Costa Norte del Perú. Registros del Fenómeno El Niño y de eventos ENSO en América del Sur. Bulletin de I'Institut Français d'Études Andines, 22 (1): 313-343; Lima.

UCEDA, S. \& CANZIANI, J., 1998 - Análisis de la secuencia arquitectónica y nuevas perspectivas de investigación en la Huaca de la Luna. In: Investigaciones en la Huaca de la Luna 1996 (Uceda, S., Mujica, E. \& Morales, R., eds.): 139-158; Trujillo: Facultad de Ciencias Sociales, Universidad Nacional de Trujillo. Proyecto Arqueológico Huaca de la Luna.

UCEDA, S. \& TUFINIO, M., 2003 - El complejo arquitectónico religioso de Huaca de la Luna: una aproximación a su dinámica ocupacional. In: Moche al final del milenio (Uceda, S. \& Mujica, E., eds.): 179-228; Lima: Fondo Editorial de la Pontificia Universidad Católica del Perú-Universidad Nacional de Trujillo. 